\title{
External cephalic version in breech presentations at term: comparison of maternal and perinatal outcome with normal pregnancies
}

\author{
Rajasekaran Anandraj ${ }^{1,2}$, Soundararaghavan $S^{1}$
}

\author{
${ }^{1}$ Department of Obstetrics \& Gynaecology, JIPMER, Pondicherry, India \\ ${ }^{2}$ Presently as Associate Professor, Department of Obstetrics \& Gynaecology, MGMCRI, Pondicherry, India
}

Received: 26 September 2013

Accepted: 8 October 2013

\section{*Correspondence:}

Dr. Rajasekaran Anandraj,

E-mail: dranandraj.mdu@gmail.com

() 2013 Anandraj R et al. This is an open-access article distributed under the terms of the Creative Commons Attribution Non-Commercial License, which permits unrestricted non-commercial use, distribution, and reproduction in any medium, provided the original work is properly cited.

\begin{abstract}
Background: To study the maternal and perinatal outcome after successful external cephalic version in term breech pregnancies and to compare the same with normal deliveries with cephalic presentation.

Methods: Singleton term breech pregnancies were included in Group I; in which ECV was attempted. Out of this, pregnancies with successful ECV (Subgroup I) were compared with Group II comprising of two term normal pregnancies delivering in labour room immediately after delivery of every woman who had successful ECV. Maternal, labour and perinatal parameters were compared between Subgroup and Group II.

Results: The two groups were comparable with respect to maternal age and gestational age. There were more multigravidae in both groups. There were more labour inductions in Subgroup. 83.3\% women in study group and $95.8 \%$ women in control group had spontaneous vaginal deliveries. There were no perinatal deaths in either group. No serious maternal complications related to version were noted.

Conclusions: This study shows that ECV does not adversely affect the maternal and perinatal outcome; although larger studies are required to confirm this. ECV may be more successful in multigravidae with flexed breech presentations. The procedure should probably be practiced regularly to improve the success rate.
\end{abstract}

Keywords: Term breech pregnancies, External cephalic version, ECV

\section{INTRODUCTION}

Breech presentation at term accounts for $3-4 \%$ of deliveries. ${ }^{1}$ Foetuses presenting by the breech have higher rates of neonatal morbidity and mortality than do foetuses with a cephalic presentation. Hence planned caesarean section at term has been increasingly used to deliver breech presenting babies at term. However this has to be balanced against the high maternal morbidity and mortality in both the index and subsequent pregnancies.

External cephalic version (ECV) is a procedure that externally rotates the foetus from a breech presentation to a vertex presentation thereby conferring on the foetus the safer mode of delivery as vertex.

External cephalic version significantly reduces the number of breech presentations at term and also reduces the high caesarean section rates for this indication. The major benefits are decreased maternal morbidity and possibly decreased costs.

This has led to the recommendation from Royal College of Obstetricians and Gynaecologists that "all women with uncomplicated breech pregnancies at term should be offered external cephalic version". ${ }^{2}$

This study explores to analyze the maternal and perinatal outcome after successful external cephalic version in term breech pregnancies.

\section{METHODS}

The study was conducted in the Department of Obstetrics and Gynaecology, Jawaharlal Institute of Postgraduate 
Medical Education and Research, Pondicherry after obtaining ethical committee approval.

Information regarding all breech deliveries occurring during the study period was collected. Women with breech presentation after 37 completed weeks were considered for the study for ECV. Women with contracted pelvis, placenta praevia, previous caesarean section or uterine surgery, amniotic fluid abnormalities, intrauterine death, major foetal anomaly and bad obstetric history were excluded from the study.

This is a comparative study involving two groups.

Group I - Term breech pregnancies in which external cephalic version is attempted.

Subgroup I (Study group) - Term breech pregnancies in which external cephalic version is successful.

Group II (Control group) - Two term normal pregnancies delivering in our labour room immediately after the delivery of a woman who had successful ECV.

\section{Sample size}

Group I - 49 .

Group II - Twice the number of cases in Subgroup I.

Patients who fulfilled the inclusion and exclusion criteria were included in Group I. An informed consent was taken. Foetal wellbeing was assessed by non stress test. A transabdominal ultrasound was done to confirm the breech presentation, rule out anomalies, locate the position of foetal spine, determine the attitude of foetal neck, position of placenta, amount of liquor and estimate foetal weight.

Patients were placed in the supine position and after applying talcum powder on the patient's abdomen, version was tried. Version was accomplished with minimum force either by the forward roll / backflip method.

Version was abandoned if:

a) there was significant foetal bradycardia

b) it was too painful / stressful

c) it could not be accomplished easily

Foetal evaluation by non stress test was done after the procedure. A second attempt was done after one week if the first one was unsuccessful. No drugs were used in the study. All patients in whom external cephalic version was successful were included in Subgroup I.

Maternal parameters like prelabour rupture of membranes, vaginal bleeding, $\mathrm{Rh}$ isoimmunization were noted. Onset of labour - spontaneous or induced, use of preinduction cervical ripening agents, duration of labour, mode of delivery - spontaneous vaginal, instrumental or caesarean section were noted. Perinatal parameters like prematurity, small for gestational age, birth weight, apgar scores at 1 minute and 5 minutes, birth asphyxia, birth injuries, congenital anomalies as well as admission to neonatal intensive care unit and duration of stay in the nursery were noted.

For each woman who delivered after successful ECV, two women with term cephalic presentation who delivered were taken as controls. Maternal, labour and perinatal parameters were noted in the control group. The parameters in both Subgroup I and control group (Group II) were compared. Statistical analysis was done using Chi - Square test.

\section{RESULTS}

There were 658 term breech presentations. Out of these, 609 women could not be considered for version because $498(82 \%)$ of them were admitted in labour and the remaining $111(18 \%)$ had contraindications for version. Of the $498(82 \%)$ women who came in labour, $218(44 \%)$ delivered vaginally -215 assisted breech deliveries and 3 breech extractions. The remaining $280 \quad(56 \%)$ were delivered by emergency caesarean section, the commonest indications being premature rupture of membranes, oligohydramnios, previous caesarean section, preeclampsia and footling breech presentation. The remaining 111 (18\%) who were not in labour but had contraindications for version were delivered by elective caesarean section, the commonest indication being previous caesarean section, oligohydramnios and foetopelvic disproportion. Therefore, only 49 women could be chosen for ECV out of 658 breech presentations $(7.44 \%)$. Out of the 49 versions performed, only 12 were successful ( $24 \%$ success rate) who constitute the study group.

\section{Maternal parameters}

Age and gestational age were similar in both the study and control groups. There were more multigravidae in both the groups. The maternal parameters are shown in table 1 .

Table 1: Maternal parameters.

\begin{tabular}{|c|c|c|c|c|}
\hline & & $\begin{array}{l}\text { Study } \\
\text { group } \\
(n=12)\end{array}$ & $\begin{array}{l}\text { Control } \\
\text { group } \\
(\mathrm{n}=24)\end{array}$ & $\begin{array}{l}\mathbf{P} \\
\text { value } \uparrow\end{array}$ \\
\hline \multicolumn{2}{|c|}{$\begin{array}{l}\text { Age in Years: } \\
\text { Mean (SD) }\end{array}$} & $\begin{array}{l}23.42 \\
(3.204)\end{array}$ & $\begin{array}{l}22.88 \\
(2.894)\end{array}$ & 0.543 \\
\hline \multirow{2}{*}{ Gravida } & Primi & 4 & 6 & \multirow{2}{*}{0.599} \\
\hline & Multi & 8 & 18 & \\
\hline \multicolumn{2}{|c|}{$\begin{array}{l}\text { Gestational age in } \\
\text { Weeks: Mean (SD) }\end{array}$} & $\begin{array}{l}39.43 \\
(1.50)\end{array}$ & $\begin{array}{l}39.96 \\
(1.11)\end{array}$ & 0.267 \\
\hline
\end{tabular}

$\dagger$ No statistical difference between the study and control groups in relation to maternal parameters. 


\section{Labour parameters}

Out of 49 women who underwent ECV, only 12 were successful. There were more inductions in the study group $(58.3 \%)$ than in the control group (29.2\%) which was not statistically significant ( $\mathrm{p}$ value $=0.091)$. Intracervical $\mathrm{PGE}_{2}$ gel was the most commonly used preinduction cervical ripening agent and it was equally used in both the groups. Ten patients in the study group (83.3\%) and 23 patients in the control group (95.8\%) had augmentation of labour ( $p$ value $=0.639$ ). Oxytocin and artificial rupture of membranes were the main modes of augmentation. Mean duration of labour was $7.77 \pm 5.92$ hours in the study group and $5.78 \pm 4.03$ hours in the control group ( $p$ value $=0.253$ ). $83.3 \%$ of women in the study group had spontaneous vaginal deliveries as against $95.8 \%$ in the control group. More women in the study group had instrumental deliveries (16.6\%) as against $4.2 \%$ in the control group. Foetal distress and failure of maternal powers were the common indications for operative vaginal delivery. There was no significant difference between the groups with regard to the indications. There were no cases of caesarean section. The labour parameters are shown in table 2.

Table 2: Labour parameters.

\begin{tabular}{|c|c|c|c|c|}
\hline \multicolumn{2}{|l|}{ Parameter } & $\begin{array}{l}\text { Study } \\
\text { group } \\
(\mathrm{n}=12)\end{array}$ & $\begin{array}{l}\text { Control } \\
\text { group } \\
(\mathrm{n}=24)\end{array}$ & $\begin{array}{l}P \\
\text { value }\end{array}$ \\
\hline \multirow{2}{*}{$\begin{array}{l}\text { Onset of } \\
\text { labour }\end{array}$} & Spontaneous & $\begin{array}{l}5 \\
(41.7 \%)\end{array}$ & $\begin{array}{l}17 \\
(70.8 \%)\end{array}$ & \multirow{2}{*}{0.091} \\
\hline & Induced & $\begin{array}{l}7 \\
(58.3 \%)\end{array}$ & $\begin{array}{l}7 \\
(29.2 \%)\end{array}$ & \\
\hline \multirow{3}{*}{$\begin{array}{l}\text { Indications } \\
\text { for induction }\end{array}$} & Pastdates & 4 & 7 & \\
\hline & $\begin{array}{l}\downarrow \text { Foetal } \\
\text { movement }\end{array}$ & 2 & 0 & \\
\hline & PROM & 1 & 0 & \\
\hline \multirow{4}{*}{$\begin{array}{l}\text { Preinduction } \\
\text { cervical } \\
\text { ripening } \\
\text { agent }\end{array}$} & $\mathrm{PGE}_{2}$ once & 5 & 5 & \multirow{4}{*}{0.276} \\
\hline & $\mathrm{PGE}_{2}$ twice & 1 & 0 & \\
\hline & Foley & 1 & 1 & \\
\hline & Foley $\rightarrow \mathrm{PGE}_{2}$ & 0 & 1 & \\
\hline \multirow{4}{*}{$\begin{array}{l}\text { Augmentation } \\
\text { of labour }\end{array}$} & No & 2 & 1 & \multirow{4}{*}{0.639} \\
\hline & ARM & 4 & 10 & \\
\hline & Oxytocin & 3 & 6 & \\
\hline & $\begin{array}{l}\mathrm{ARM} \rightarrow \\
\text { Oxytocin }\end{array}$ & 3 & 7 & \\
\hline \multicolumn{2}{|c|}{ Duration of labour (hours) } & $\begin{array}{l}7.77 \pm \\
5.92\end{array}$ & $\begin{array}{l}5.78 \pm \\
4.03\end{array}$ & 0.253 \\
\hline \multirow{2}{*}{$\begin{array}{l}\text { Mode of } \\
\text { delivery }\end{array}$} & $\begin{array}{l}\text { Spontaneous } \\
\text { vaginal }\end{array}$ & $\begin{array}{l}10 \\
(83.3 \%)\end{array}$ & $\begin{array}{l}23 \\
(95.8 \%)\end{array}$ & \multirow{2}{*}{0.201} \\
\hline & $\begin{array}{l}\text { Operative } \\
\text { vaginal }\end{array}$ & $\begin{array}{l}2 \\
(16.6 \%)\end{array}$ & $1(4.2 \%)$ & \\
\hline \multirow{2}{*}{$\begin{array}{l}\text { Indications } \\
\text { for operative } \\
\text { vaginal } \\
\text { delivery }\end{array}$} & Foetal distress & 1 & 1 & \\
\hline & $\begin{array}{l}\text { Failure of } \\
\text { powers }\end{array}$ & 1 & 0 & \\
\hline
\end{tabular}

\section{Perinatal parameters}

Mean birth weight of babies in the study group was 2.888 $\pm 0.2873 \mathrm{~kg}$ whereas it was $2.926 \pm 0.4046 \mathrm{~kg}$ in the control group $(\mathrm{p}$ value $=0.827)$. There was one small for gestational age baby in the study group. There were no stillbirths in either group. One patient in the study group came for admission 34 days after ECV with premature rupture of membranes. She had instillation of intracervical $\mathrm{PGE}_{2}$ gel twice for cervical ripening followed by labour induction with oxytocin and delivered by low forceps (indication - foetal distress). The baby had a one minute apgar of 5 and a five minute apgar of 7 . The baby was shifted to NICU for respiratory distress where a subgaleal haematoma was diagnosed. The baby was given blood transfusion and was discharged from NICU after 2 days.

\section{Complications of ECV}

Out of the 49 versions attempted, ten patients had foetal bradycardia during the procedure. The procedure was abandoned and the foetal presentation was reverted to breech. Ultrasonography was done to exclude abruption placenta, cord entanglement, and for observation of the foetal heart motion. Two patients had sustained bradycardia $(<60 \mathrm{bpm})$ and were delivered by caesarean section. A reactive non stress test was obtained in the remaining eight patients. All the eight cases were delivered by elective caesarean section.

None of the patients had vaginal bleeding or onset of labour within 24 hours of attempted version. There was one case of premature rupture of membranes 34 days after successful ECV. No serious maternal complications related to version were noted.

\section{DISCUSSION}

There were 658 term breech presentations. Out of these, 609 women could not be considered for version because $498(82 \%)$ of them were admitted in labour and the remaining $111(18 \%)$ had contraindications for version. Therefore, only 49 women could be chosen for ECV out of 658 breech presentations $(7.44 \%)$. Out of the 49 versions performed, only 12 were successful $(24 \%$ success rate) who constitute the study group.

In the study by Hofmeyr, 60 out of 67 patients were selected for ECV; the reasons for exclusion were nonreactive foetal heart rate patterns, markedly contracted pelvis, severe obesity and $\mathrm{Rh}$ negative status. ${ }^{3}$ In the study by Stine et al, 148 patients were selected for ECV and 41 were excluded because of contraindications like immobile or engaged breech, oligohydramnios, patient refusal, suspected growth retardation, abnormal GTT or suspected DM, abnormal baseline NST. ${ }^{4}$

In the current study, out of the 49 versions performed, only 12 were successful ( $24 \%$ success rate) who constitute the 
study group. Similarly in the study by Van Veelen et al, the success rate for ECV was $26 \%$ of attempts (48 out of 188 attempts performed in 89 patients), ${ }^{5}$ but in the study by Lau et al, ECV was successful in $69.5 \%$ attempts (169 out of 243 performed in 241 term breech pregnancies). ${ }^{6}$

\section{Maternal parameters}

In our study, 28 out of 49 women $(57 \%)$ considered for the study were multiparae. In the study by Van Veelen et al, the ECV group comprised of 40 nullipara and 50 multipara. ${ }^{5}$ In the study by Lau et al (2000), there were 184 nulliparous women who constituted $43.3 \%$ of ECV group. ${ }^{7}$ The mean gestational age of women considered for our study was $39.24 \pm 2.2$ weeks, whereas it was 37.5 \pm 0.93 weeks in the study by Hofmeyr and 38 weeks in the study by Lau et al.

\section{Labour parameters}

Although external cephalic version at term effectively reduces the incidence of breech presentation at delivery, the incidence of intrapartum caesarean section after successful ECV has been reported to be around 20 to $30 \%$ especially among those studies with a large number of cases. However, virtually all studies have excluded cases that are at high risk for caesarean section. Therefore an incidence of 20 to $30 \%$ of abdominal delivery among this highly selected group of patients was exceptionally high. We had no case of caesarean section after successful version. The success rates of ECV and caesarean section rates after successful ECV are given in table 3.

Table 3: Incidence of CS after ECV.

\begin{tabular}{|llll|}
\hline Authors & $\begin{array}{l}\text { No of } \\
\text { cases of } \\
\text { ECV }\end{array}$ & $\begin{array}{l}\text { Success } \\
\text { rate of } \\
\text { ECV \% }\end{array}$ & $\begin{array}{l}\text { CS after } \\
\text { successful } \\
\text { ECV \% }\end{array}$ \\
\hline Brocks et al $^{8}$ & 31 & 41 & 0 \\
\hline $\begin{array}{l}\text { Van Dorsten } \\
\text { et al }\end{array}$ & 25 & 68 & 5.9 \\
\hline Stine et al $^{4}$ & 148 & 73 & 24 \\
\hline Lau et al $^{6}$ & 243 & 69.5 & 26 \\
\hline Present study & 49 & 24 & 0 \\
\hline
\end{tabular}

\section{Perinatal parameters}

In the study by Brocks et al, 2 babies out of 41 in the study group had a one minute apgar $<7 .{ }^{8}$ In the study by Lau et al, the mean birth weight was $3.26 \pm 0.435 \mathrm{~kg} .{ }^{6}$ There were no significant neonatal complications. All babies had a 5 minute apgar $\geq 8$.

\section{Complications of ECV}

Stine et al reported a $39 \%$ incidence of foetal heart rate changes which included variable decelerations, bradycardia, tachycardia, sinusoidal pattern and decreased baseline variability. Most FHR changes were transient and resolved with cessation of manipulation and they were not associated with a less favourable outcome to the foetus. ${ }^{4}$ But in the study by Van Veelen et al, transient foetal bradycardia was noted in only 1 out of 89 patients who underwent ECV. ${ }^{5}$

\section{Possible causes of low success rate}

In our study, 21 out of 49 cases (46\%) were primigravidae. The success rate in primigravidae was $19 \%$ as compared to $29 \%$ in cases of multigravidae; though this was not statistically significant $(\mathrm{p}=0.517)$. In a randomized controlled trial by Brocks et al, a significant correlation of primiparity to failed version was reported $(77 \%$ failures, $\mathrm{p}<0.01) ;^{8}$ whereas in the study by Stine et al, there was no difference between successful and unsuccessful version groups with regard to parity. ${ }^{4}$

Twenty cases $(54 \%)$ in our study had placenta situated on the anterior uterine wall as determined by ultrasonography. In the study by Schorr et al, anterior placentation did not affect the success rate; ${ }^{10}$ but Brocks et al found a significant correlation of anterior placental location to failure of $\operatorname{ECV}(59 \%$ failures, $\mathrm{p}<0.025){ }^{8}$

In our study, $84 \%$ of breech presentations were of the frank or extended type. In the study by Stine et al, there was no difference between successful and unsuccessful version groups with regard to type of breech presentation; ${ }^{4}$ but Hofmeyr reported that ECV tended to be more difficult in patients with frank breech presentation. ${ }^{3}$

Foetal spine was anterior in 2 cases and posterior in 1 case in our study making it difficult for ECV.

No tocolysis was used in our study to facilitate version. There were higher success rates in studies by Van Dorsten et al $(68 \%)$ and Morrison et al $(68 \%)$ using tocolytics. ${ }^{9,10}$

No inhalational or regional anaesthesia was used in our study to facilitate version. The success rates by Schorr et al and Carlan et al were 51\% and 59\% respectively using epidural anaesthesia with $2 \%$ lidocaine and terbutaline for tocolysis. ${ }^{11,12}$

It is possible that the criteria for selection of patients for version were too stringent thereby limiting the number of patients chosen to only $7.44 \%$. Since ECV is an infrequently performed procedure, the limited experience of the obstetricians may also be a reason for the low success rate of ECV.

\section{CONCLUSIONS}

From the present study, it may be concluded that ECV does not adversely affect the maternal and perinatal outcome. ECV may be more successful in multigravidae with flexed breech presentation. The procedure should 
probably be practiced regularly to improve the success rate.

Funding: None

Conflict of interest: None

Ethical approval: Approved by the institute ethical committee

\section{REFERENCES}

1. Cruikshank DP. Breech presentation. Clin Obstet Gynecol. 1986; 29: 255-263.

2. Royal college of Obstetricians and Gynaecologists [homepage on the internet]. Greentop guidelines: External cephalic version (ECV) and reducing the incidence of breech presentation (Green-top 20a); 2006 [published 01/12/2006]. Available from: http:// rcog.org.uk/guidelines/external cephalic version and reducing incidence of breech presentation/

3. Hofmeyr GJ. Effect of external cephalic version in late pregnancy on breech presentation and caesarean section rate: a controlled trial. BJOG. 1983; 90:392399.

4. Stine LE, Phelan JP, Wallace R. Update on external cephalic version performed at term. Obstet Gynecol. 1985; 65: 642-646.

5. Van Veelen AJ, Van cappellen AW, Flu PK, Straub MJ, Wallenburg HC. Effect of external cephalic version in late pregnancy on presentation at delivery: a randomized controlled trial. BJOG. 1989; 96: 916-921.
6. Lau TK, Wing K, Rogers M. Pregnancy outcome after successful external cephalic version for breech presentation at term. Am J Obstet Gynecol. 1997; 176: 218-223.

7. Lau TK, Leung TY, Kit Lo KW, Fok WY, Rogers MS. Outcome of labour after successful external cephalic version at term complicated by isolated transient fetal bradycardia. BJOG. 2000; 107: 401405.

8. Brocks V, Philipsen T, Secher NJ. A randomized trial of external cephalic version with tocolysis in late pregnancy. BJOG. 1984; 91: 653-656.

9. Van Dorsten JP, Schifrin BS, Wallace RL. Randomized control trial of external cephalic version with tocolysis in late pregnancy. Am J Obstet Gynecol. 1981; 141: 417-424.

10. Morrison JC, Myatt RE, Martin JN, Meeks GR, Martin RW, Bucowaz ET, et al. External cephalic version of the breech presentation under tocolysis. Am J Obstet Gynecol. 1986; 154: 900-903.

11. Schorr SJ, Speights SE, Ross EL, Bofill JA, Rust OA, Norman PF, et al. A randomized trial of epidural anesthesia to improve external cephalic version success. Am J Obstet Gynecol. 1997; 177: 1133-1137.

12. Carlan SJ, Dent JM, Huckaby T, Whittington EC, Shaefer D. The effect of epidural anesthesia on safety and success of external cephalic version at term. Anesth Analg. 1994; 79: 525-528.

DOI: $10.5455 / 2320-1770 . i j r \operatorname{cog} 20131218$

Cite this article as: Anandraj R, S

Soundararaghavan. External cephalic version in breech presentations at term: comparison of maternal and perinatal outcome with normal pregnancies. Int J Reprod Contracept Obstet Gynecol 2013;2:581-5. 